\title{
Russell's diencephalic syndrome of early childhood
}

\author{
MICHAEL A. SALMON \\ From the Park Hospital for Children, Oxford, and Stoke Mandeville Hospital
}

SUMMARY A case of Russell's diencephalic syndrome of early childhood is presented and the world literature reviewed. Assays of serum growth hormone $(\mathrm{HGH})$ and fat mobilizing substance (FMS) were performed and gave very abnormal results. The role of these two substances is discussed and their value in the diagnosis of this syndrome is emphasized.

Within the last two decades interest has been focused on the diencephalon and its pathology, and it is now known that discrete organic lesions of the hypothalamus and adjacent structures may produce characteristic symptoms. Thus, it has been known for very many years that posteriorly placed tumours of the hypothalamus may be associated with precocious puberty, somnolence, obesity, diabetes insipidus, dysthermia, and various emotional disturbances. Some conditions, however, such as leprechaunism (Donohue's syndrome), cerebral gigantism (Soto's syndrome), generalized lipodystrophy with gigantism, and possibly progeria (Hutchinson-Gilford syndrome) may be due to a functional disorder of the diencephalon rather than to a discrete organic lesion within one or more of its component structures. It was not, however, until 1951 that Russell described an apparently specific syndrome of early childhood resulting from a neoplastic lesion of the anterior hypothalamus, and not until 1957 that Lorimer Dods became the second author to report further examples of the syndrome. Russell would appear to be the only author to report cases from the United Kingdom.

Russell's syndrome is probably much more common than the 50 cases in the literature would suggest and the purpose of this paper is to describe a further case from the United Kingdom with the results of relevant investigations and treatment.

\section{CASE REPORT}

S.H., a girl aged 23 months, was the first child of elderly parents (maternal age, 43 years; paternal age, 45 years). She presented with a three month history of rapid, progressive weight loss and sleep reversal. The mother had been a ward sister on a well-known neurological unit. The first 20 months of life had been uncomplicated but after this time there was a dramatic change (Figs 1 and 2). In spite of an apparently normal dietary intake she rapidly lost weight (Fig. 3) and at the same time became hyperactive by night with long periods of sleep by day. While in the ward she appeared affectionate, without aggression, but hyperkinetic. She talked and sang to herself incessantly and demonstrated slight ataxia on

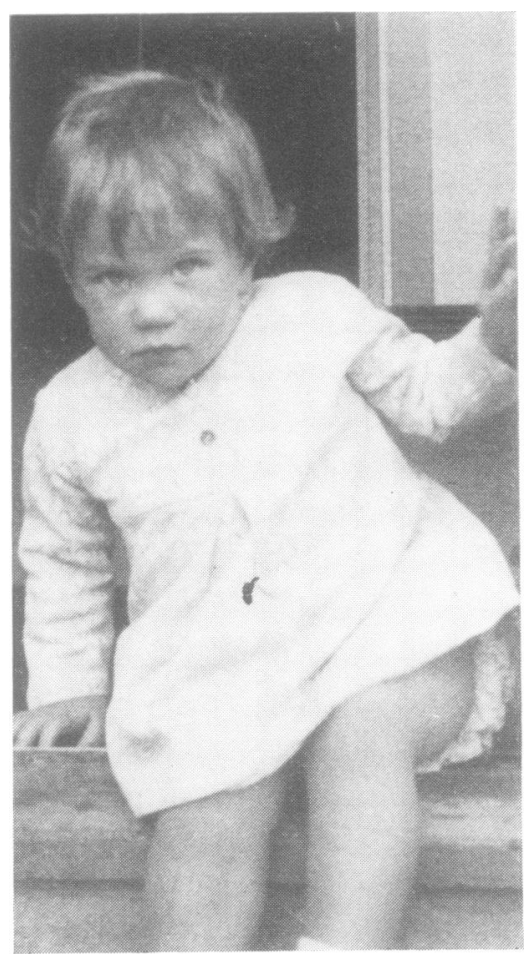

FIG. 1. S.H. at age 20 months. 
turning and reaching out for objects. Clinical examination revealed, apart from gross marasmus, nystagmus and numerous café-au-lait patches over her upper trunk. Her body temperature was consistently about $35 \cdot 6^{\circ} \mathrm{C}\left(96^{\circ} \mathrm{F}\right)$ and never exceeded this. There was no polydipsia or polyuria and her appetite was usually normal. Her hcight and weight, from measurements kept by the parents, both followed the 97th percentile, but the weight dropped to well below the 3rd percentile in just over three months. During this period of time her height did not leave the 97 th percentile.

INVESTIGATIONS The results of the following investigations were within normal limits: Haemoglobin, sedimentation rate, urea, plasma electrolytes, cholesterol, calcium, phosphorus, alkaline phosphatase, plasma proteins, random and fasting blood glucose, D-xylose absorption test, serum lead, protein bound iodine, and electroencephalograph. Urine specific gravity was consistently over 1,010 .

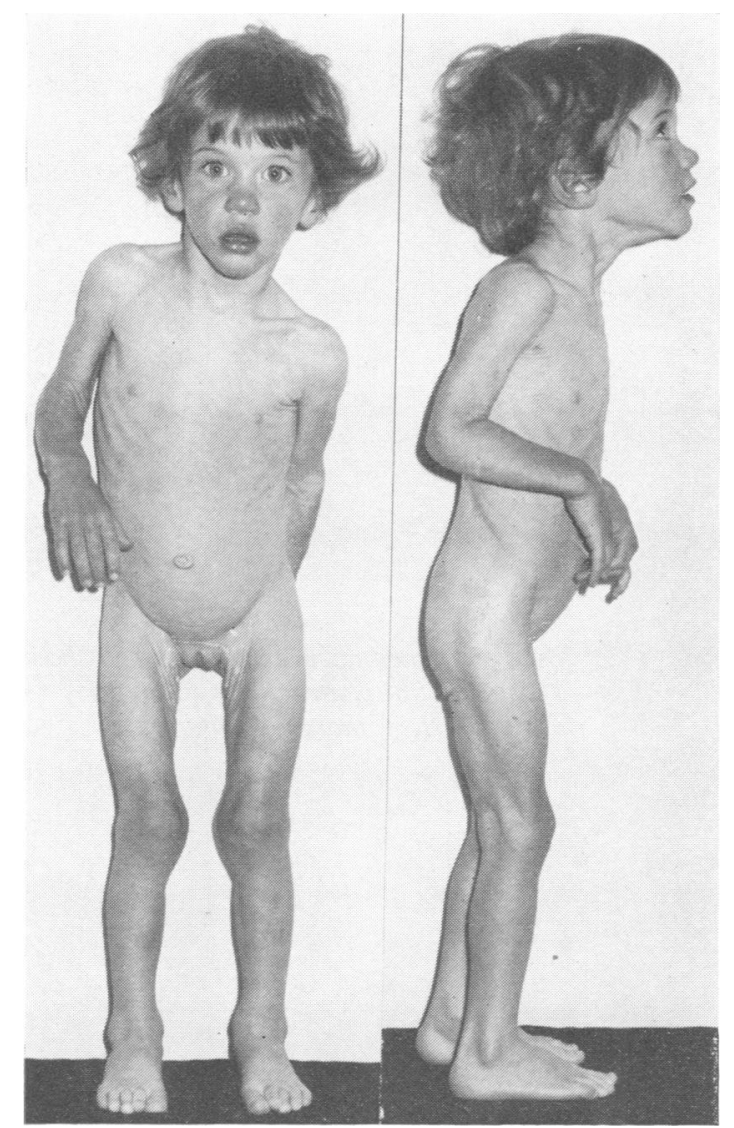

FIG. 2. S.H. at age 23 months to show extreme wasting.

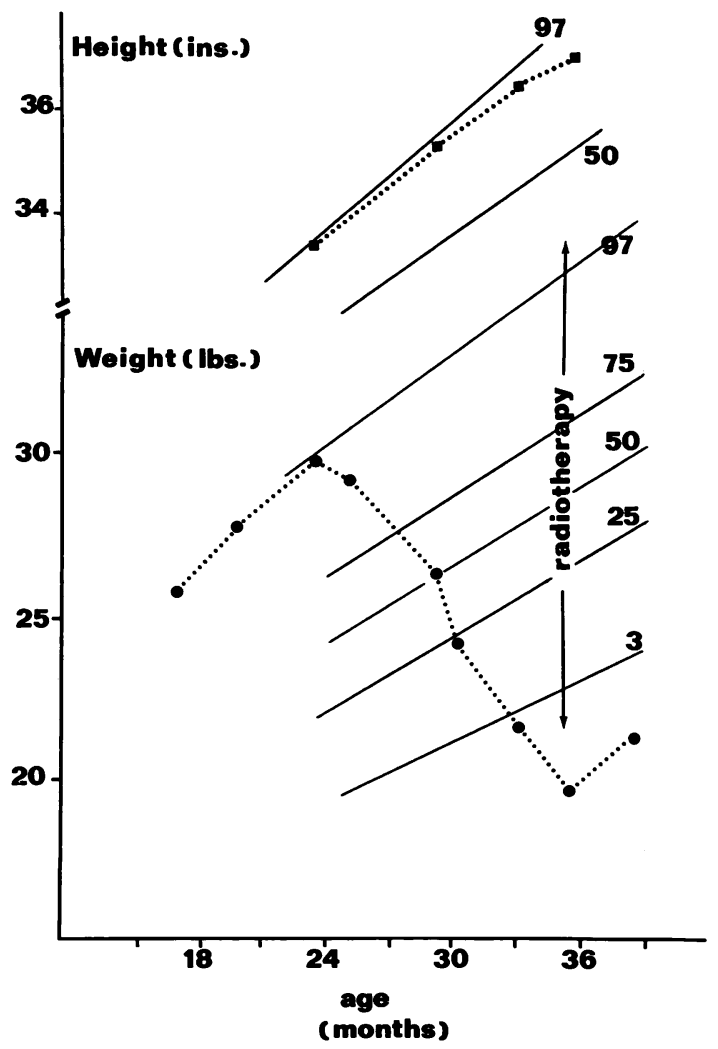

FIG. 3. Height and weight chart.

Abnormal results The cerebrospinal fluid contained protein $100 \mathrm{mg} / 100 \mathrm{ml}$. A pneumoencephalogram showed a large and mainly left-sided anterior hypothalamic tumour (Figs 4 and 5) indenting the third ventricle.

The cisterna lamina terminalis was displaced forwards and the interpeduncular system was obliterated. The tumour also encroached on the upper part of the prepontine cisterns and displaced the lower margin of the left frontal horn upwards and forwards. The aqueduct was rather more upright than normal and the midbrain was displaced backwards.

Serum growth hormone (HGH) was assayed using a double antibody radioimmunoassay technique as described by Jackson, Grant, and Clayton (1968); HGH production was stimulated with oral Bovril $\left(20 \mathrm{~g} / 1.5 \mathrm{~m}^{2}\right.$ given in $160 \mathrm{ml}$. warm water) and estimated in venous blood samples taken from an indwelling intravenous cannula. The results obtained were comparable with those expected in an adult subject with acromegaly (Table 1). A similar assay was performed eight months after radiotherapy.

Urinary fat mobilizing substance (FMS) was assayed by the method of Pawan (1969). Plasma levels of ketones (as acetone) and free fatty acids (FFA) were measured in mice injected with prepared 


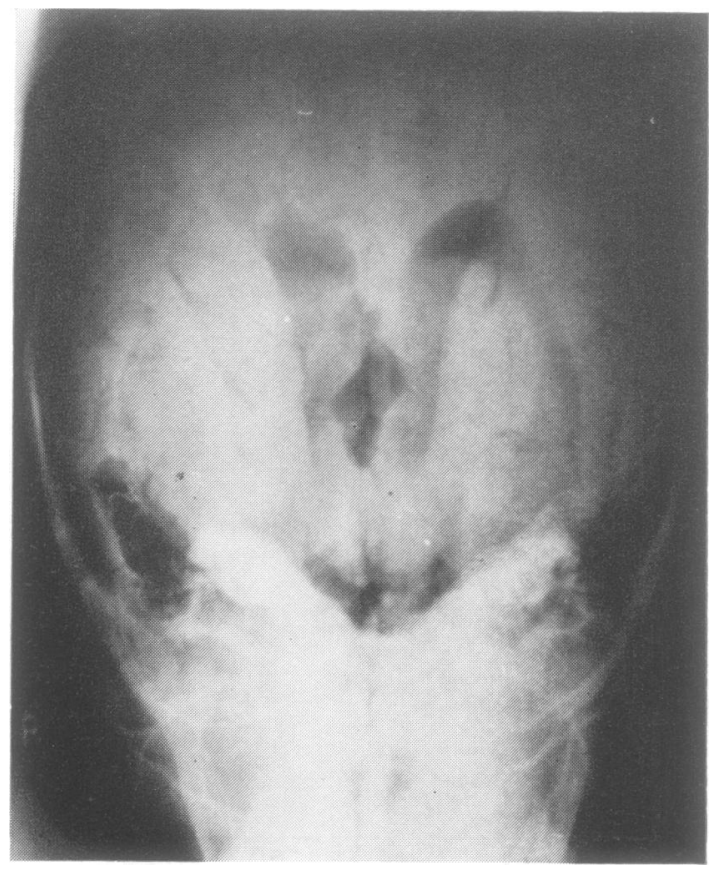

FIG. 4. Pneumoencephalogram to show distortion $\stackrel{\mathbb{\Phi}}{\varrho}$ of third ventricle.
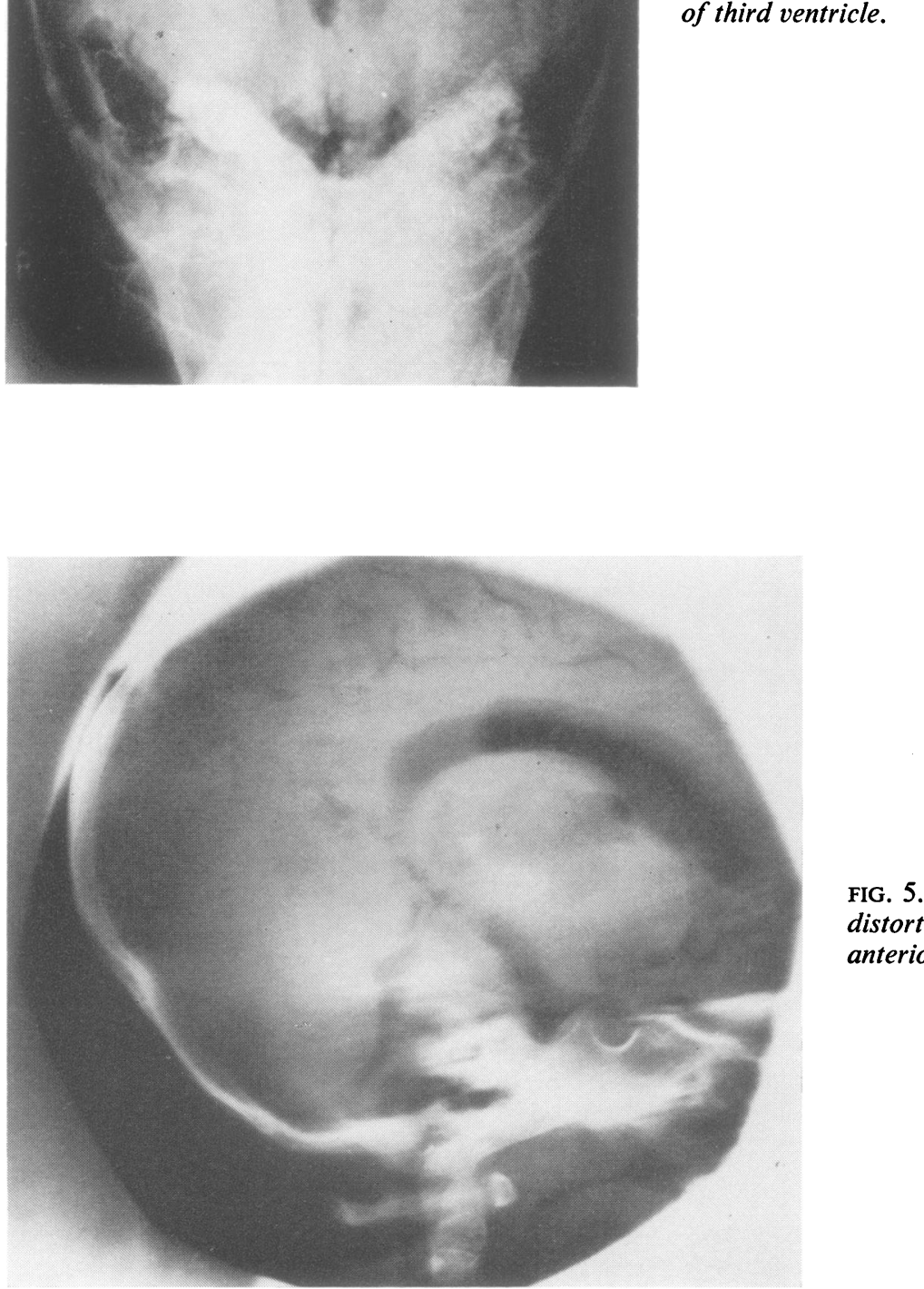

FIG. 5. Pneumoencephalogram to show distortion of ventricular system by anterior hypothalamic tumour. 
TABLE 1

SERUM GROWTH HORMONE (HGH) ASSAY

\begin{tabular}{lccc}
\hline $\begin{array}{l}\text { Time } \\
(\mathrm{min})\end{array}$ & $\begin{array}{c}\text { Normal values } \\
(\mu I \mathrm{I} / \mathrm{ml} .)\end{array}$ & $\begin{array}{c}\text { Before treatment } \\
(\mu I u / m l .)\end{array}$ & $\begin{array}{c}\text { Three months after } \\
\text { radiotherapy } \\
(\mu I \mathrm{I} / \mathrm{ml} .)\end{array}$ \\
\hline Fasting & $0-10$ & $93 \cdot 5$ & 48.8 \\
30 & & $>200$ & 68.8 \\
60 & maximum rise & $>200$ & $71 \cdot 6$ \\
90 & $30-40$ & $>165$ & 54.8 \\
120 & & $>143$ & 40.0 \\
150 & & 84.5 & 27.4 \\
\hline
\end{tabular}

urine (see Kekwick and Pawan, 1967) and compared with results obtained from a control series of mice injected with saline. From the increase in plasma ketones the assay revealed a very great deal $(74 \%$ increase) of FMS activity. Unfortunately, the assay was performed three months after radiotherapy and it would have been interesting to have measured FMS activity before treatment.
Ketones

(as acetone)

Control mice $\quad 2 \cdot 21 \mathrm{mg} / 100 \mathrm{ml}$.

Test mice
Free fatty

acids

$558 \mu \mathrm{E} / 1$.

$599 \mu \mathrm{E} / 1$.

$(7 \%$ inc.)
At the time of this assay the patient was on a normal diet and eating well. In Pawan's series of 72 normal subjects there was no percentage increase of ketones or free fatty acids in mouse plasma, and a similar finding was reported in six subjects after pituitary ablation.

TREATMENT AND PROGRESS Once the diagnosis of a large anterior hypothalamic tumour was confirmed radiotherapy was given as surgery was considered impossible. A total of 4,650 r were delivered by cobalt $\gamma$-ray therapy to the tumour over 19 sessions (44 days). After this course of radiation a slight improvement was noticed in the succeeding months. Three months after treatment she had gained a little weight and was much less hyperkinetic. There was, however, a sinister decrease in the child's visual acuity and it is likely that there is considerable involvement of the optic chiasma. Formal perimetry was not attempted.

\section{DISCUSSION}

The case described conforms to the original description by Russell (1951) of the diencephalic syndrome which bears his name. In reviewing the world literature there is found to be a great similarity between the described cases and the definition of a specific syndrome must be confirmed (Table 2).

Children with Russell's diencephalic syndrome commonly present in the first year of life and probably never after the age of 5 years. The youngest reported cases were those of Dods (1957) and Smith, Weinburg, and McAlister (1964) who presented at the age of 2 months.

TABLE 2

REPORTED FINDINGS IN 29 CASES OF RUSSELL'S DIENCEPHALIC SYNDROME

\begin{tabular}{ll}
\hline 1. Profound cachexia & $29 / 29$ \\
2. Sex incidence & $18 \sigma / 11$ 足 \\
3. Euphoria & mentioned in $16 / 29$ \\
4. Hyperactivity & mentioned in $20 / 29$ \\
5. Nystagmus & mentioned in $16 / 29$ \\
6. Optic atrophy & $9 / 29$ \\
7. Pallor without anaemia & mentioned in $14 / 29$ \\
8. Anterior hypothalamic tumour & $29 / 29$ \\
9. Age at presentation & $2-32$ months \\
\hline
\end{tabular}

In virtually all the cases profound emaciation with hyperactivity, apparent well-being, and euphoria were prominent and, apart from nystagmus, there was a gross paucity of neurological signs. In no case was there evidence of raised intracranial pressure, but extension of the tumour to involve the optic discs was present in about one fifth of the cases. Paradoxical obesity and increased height occurred in a case described by Fishman and Peake (1970) and was thought to be secondary to extension of the tumour to involve hypothalamic centres regulating food intake. Similar changes occurred in one of the cases described by Gamstorp, Kjellman, and Palmgren (1967) after partial surgical removal of an anterior hypothalamic tumour.

Apart from gross, progressive subcutaneous wasting, these children exhibit a curious euphoria and lack of aggression which Spiegel, Wycis, Marks, and Lee (1947) attribute to interruption of the frontothalamic-hypothalamic pathway or even to discrete involvement, by the tumour, of the dorsomedial thalamic nuclei.

Growth hormone (HGH) assay has been made in only two patients other than that presented here, but the exact levels of $\mathrm{HGH}$ in one of these (Smith et al., 1964) is not recorded. In both cases the levels were markedly raised. In the present case the levels recorded, both in the fasting state and after-stimulation with Bovril 
(Jackson et al., 1968) were greatly raised and equivalent to those expected in adults with acromegaly. These high levels were not associated with any increase in height although sustained high levels of growth hormone should increase linear growth (Daughaday, 1968). Three months after treatment with radiotherapy a second HGH assay was performed and showed a substantial drop in HGH levels when compared with the first assay. The levels were, however, still above those expected in normal subjects. The effect of excess HGH production in this syndrome is not fully understood but it is probable that its described lipolytic action (Zierler and Rabinowitz, 1963) is, in part, responsible for dispersing subcutaneous fat, which Poznanski and Manson (1963) showed to be completely absent. Similar loss of subcutaneous fat is seen in other conditions of presumed diencephalic origin-namely, leprechaunism (Donohue and Uchida, 1954; Salmon and Webb, 1963), progeria (Schinz, Baensch, Friedl, and Uehlinger, 1952; Thomson and Forfar, 1950), and generalized lipodystrophy (Berardinelli, 1954; Seip and Trygstad, 1963; Fairney, Lewis, and Cottom, 1969). It is of interest to recall that Villee, Nichols, and Talbot (1969) showed that growth in progeria was also unresponsive to $\mathrm{HGH}$. In leprechaunism the only report of $\mathrm{HGH}$ assay is an isolated measurement reported by Dekaban (1965) which is at the upper level of the normal fasting range (1-10 $\mu \mathrm{Iu} / \mathrm{ml})$. The total lack of subcutaneous fat in Russell's diencephalic syndrome may be partly attributable to increased production of $\mathrm{HGH}$, but the lipid mobilizing fraction (LM) isolated by Zarafonetis, Seifter, Baeder, and Kalas (1959) from the pituitary and the fat mobilizing polypeptide (FMS) isolated from urine by Chalmers, Pawan, and Kekwick (1960) may also play their part. These last two substances may be quite unrelated to HGH but Pawan (1971) suggests that FMS may in fact prove to be a degradation product of HGH. FMS activity was estimated in the present case and found to be significantly raised. The estimation was made three months after radiotherapy had produced clinical improvement and a slight gain in weight. At this time $\mathrm{HGH}$ assay (Table 1) revealed a considerable drop from the pretreatment levels. It would be of the greatest interest to assay FMS before treatment in this syndrome.

In 1960 Murray found that specific stimulation of the anterior hypothalamus in dogs produced fluctuating levels of blood lipids. Since pituitary hormones are thought to be underr hypothalamic control, it is possible that liped depletion may result from the action, direct or otherwise, of a specific humoral substance pr\$duced by the presence of the anterior hypothalamic tumour in this syndrome.

With the exception of one case seen by Dow (1957) where a clinical picture resembling Russell's syndrome resulted from a midline cerebellar astrocytoma, all the lesions wefe accurately located in the anterior hypothalam and extended upwards to displace the floor $\overline{\text { of }}$ the third ventricle. Extension forwards to invol be the optic tracts was common. The tumours were commonly astrocytomas but oligodendrogli mas, spongioblastomas, and ependymomas have all been recorded. In one case (Braun and Forney, 1959) a perforated duodenal ulcer wi massive haemorrhage complicated the main presentation, although we should recall that the association of peptic ulceration with intracranial neoplasm was noticed as long ago as 1850 bo Rokitansky and again in 1932 by Cushing.

The presentation of Russell's syndrome isso stereotyped that diagnosis should not o difficult. The profound cachexia with hy activity and a happy affectionate child shoulstbe contrasted with the cachectic picture of chro starvation, severe malabsorption, gastroenteritif neoplasia in general, anorexia nervosa, thyros toxicosis, and chronic diabetes.

The absence of neurological signs is importan although nystagmus may be present. Air studies and growth hormone assay should confirm the diagnosis. Treatment is at the best palliative and neurosurgery may be impossible. Fishman an Peake (1970) record a six year survival aftexi radiotherapy in one case, but few patients suF vive one year after the initial diagnosis.

My special thanks are due to Mrs. D. B. Jacksoan (Institute of Child Health, London) for HGH assays and to Dr. Gaston Pawan (Medical Unit, The Middlesex Hospital, London) for FMS assays. $¥$ would like to thank Dr. Dermod MacCarthy, to whom this patient was initially referred, and D? Hugh Ellis, who provided facilities for many of th: investigations.

\section{REFERENCES}

Berardinelli, W. (1954). An undiagnosed endocrinometabolic syndrome. Report of 2 cases. Journal of Clinical End\&crinology and Metabolism, 14, 193-204.

Braun, F. C., Jr., and Forney, W. R. (1959). Diencephalic syndrome of early infancy associated with brain tumoro 
Report of a case and review of the literature. Pediatrics, 24, 609-615.

Chalmers, T. M., Pawan, G. L. S., and Kekwick, A. (1960). Fat-mobilising and ketogenic activity of urine extracts: relation to corticotrophin and growth hormone. Lancet, 2, 6-9.

Cushing, H. (1932). Peptic ulcers and the interbrain. Surgery, Gynecology, and Obstetrics, 55, 1-34.

Daughaday, W. H. (1968). The adenohypophysis. In Textbook of Endocrinology, 4th edn, pp. 27-84. Edited by R. H. Williams. Saunders: Philadelphia.

Dekaban, A. (1965). Metabolic and chromosomal studies in leprechaunism. Archives of Disease in Childhood, 40, 632636.

Dods, L. (1957). A diencephalic syndrome of early infancy. Medical Journal of Australia, 2, 689-691.

Donohue, W. L., and Uchida, I. (1954). Leprechaunism. A euphuism for a rare familial disorder. Journal of Pediatrics, 45, 505-519.

Fairney, A., Lewis, G., and Cottom, D. (1969). Total lipodystrophy. Archives of Disease in Children, 44, 368-372.

Fishman, M. A., and Peake, G. T. (1970). Paradoxical growth in a patient with the diencephalic syndrome. Pediatrics, 45, 973-982.

Gamstorp, I., Kjellman, B., and Palmgren, B. (1967). Diencephalic syndromes of infancy. Journal of Paediatrics, 70, 383-390.

Jackson, D., Grant, D. B., and Clayton, B. E. (1968). A simple oral test of growth-hormone secretion in children. Lancet, 2, 373-375.

Kekwick, A., and Pawan, G. L. S. (1967). Fat mobilizing substance (FMS). Metabolism, 16, 787-796.

Murray, G. (1960). Fat embolism and a fat center. American Journal of Surgery, 100, 676-681.

Pawan, G. L. S. (1969). Levels of fat mobilizing substance (FMS) in urine of human subjects in physiological and pathological conditions of increased lipid metabolism. Proceedings of the Nutrition Society, 28, 17-18.
Pawan, G. L. S. (1971). Personal communication.

Poznanski, A. K., and Manson, G. (1963). Radiographic appearance of the soft tissues in the diencephalic syndrome of infancy. Radiology, 81, 101-106.

Rokitansky, C. (1850). A Manual of Pathological Anatomy, Vol. 3, p. 40. Philadelphia.

Russell, A. (1951). A diencephalic syndrome of emaciation in infancy and childhood. Archives of Disease in Childhood, 26, 274.

Salmon, M. A., and Webb, J. N. (1963). Dystrophic changes associated with leprechaunism in a male infant. Archives of Disease in Childhood, 38, 530-535.

Schinz, H. R., Baensch, W. E., Friedl, E., and Uehlinger, E. (1952). Roentgen-diagnostics, vol. 2, pp. 1122-1123. Grune and Stratton: New York.

Seip, M., and Trygstad, O. (1963). Generalized lipodystrophy. Archives of Disease in Childhood, 38, 447-453.

Smith, K. R., Jr., Weinburg, W. A., and McAlister, W. H. (1965). Failure to thrive: the diencephalic syndrome of infancy and childhood. A case report. Journal of Neurosurgery, 23, 348-351.

Spiegel, E. A., Wycis, H. T., Marks, M., and Lee, A. J. (1947). Stereotaxic apparatus for operations on the human brain. Science, 106, 349-350.

Thomson, J., and Forfar, J. O. (1950). Progeria (HutchinsonGilford syndrome). Report of a case and review of the literature. Archives of Disease in Childhood, 25, 224-234.

Villee, D. B., Nichols, G., Jr., and Talbot, N. B. (1969). Metabolic studies in two boys with classical progeria. Pediatrics, 43, 207-216.

Zarafonetis, C. J. D., Seifter, J., Baeder, D. H., and Kalas, J. P. (1959). Current clinical status of lipid-mobilizer hormone. Archives of Internal Medicine, 104, 974-981.

Zierler, K. L., and Rabinowitz, D. (1963). Roles of insulin and growth hormone, based on studies of forearm metabolism in man. Medicine, 42, 385-402. 